Sandra Fancello, Les aventuriers du pentecôtisme ghanéen. Nation, conversion et délivrance en Afrique de l'Ouest

Paris, IRD-Karthala, 2006, 378 p.

\title{
André Corten
}

\section{OpenEdition}

\section{Journals}

Édition électronique

URL : http://journals.openedition.org/assr/10633

DOI : $10.4000 /$ assr. 10633

ISSN : $1777-5825$

Éditeur

Éditions de l'EHESS

Édition imprimée

Date de publication : 1 décembre 2007

Pagination : 157-310

ISBN : 978-2-7132-2145-3

ISSN : 0335-5985

\section{Référence électronique}

André Corten, «Sandra Fancello, Les aventuriers du pentecôtisme ghanéen. Nation, conversion et délivrance en Afrique de l'Ouest », Archives de sciences sociales des religions [En ligne], 140 | octobre décembre 2007, document 140-30, mis en ligne le 02 juillet 2008, consulté le 21 septembre 2020. URL : http://journals.openedition.org/assr/10633 ; DOI : https://doi.org/10.4000/assr.10633 


\title{
Sandra Fancello, Les aventuriers du pentecôtisme ghanéen. Nation, conversion et délivrance en Afrique de l'Ouest
}

Paris, IRD-Karthala, 2006, 378 p.

\author{
André Corten
}

1 Le pentecôtisme est fort étudié depuis quelque temps. De nombreux écrits récents ont porté sur ce qu'on appelle le "néo-pentecôtisme», un "néo-pentecôtisme» qui a souvent un caractère transnational. Le mérite de ce livre est de porter sur un pentecôtisme «historique », pourtant lui aussi transnational. Il s'agit de Church of Pentecost, originaire du Ghana et qui est aujourd'hui la première Église pentecôtiste du pays. Celle-ci est connue en Côte d'Ivoire, au Burkina Faso, au Bénin, au Togo et en France sous le nom d'Église de Pentecôte confondant son nom avec d'autres Églises de Pentecôte répandue dans le continent (notamment au Rwanda). La Church of Pentecost est, en fait, une des plus importantes Églises africaines transnationales (présente dans une quarantaine de pays) et c'est précisément l'étude quasi ethnographique de cette institution qui fait l'originalité du livre de Sandra Fancello. Cette Église avait déjà fait l'objet d'analyses remarquables, de Birgit Meyer, de Rijk Van Dijk et de Gerrie ter Haar - notons également celle de Cédric Mayrargue sur le Bénin -, mais jamais au carrefour d'une étude de cas et d'un phénomène de transnationalisation, jamais non plus dans son influence sur toute l'aire francophone.

2 Contrairement au développement des Églises pentecôtistes en Afrique du Sud où les Africains feront scission en Églises zionites (de type Églises africaines indépendantes), la Church of Pentecost, fondée en 1952 par un missionnaire écossais dissident, sera profondément africaine ou peut-être faut-il dire akan (du nom de l'ethnie akan propre au Ghana) y compris par l'usage de la langue vernaculaire, le twi, comme langue rituelle. Voilà donc une Église missionnaire "indigène»! Il faut ajouter que les Ghanéens n'ont jamais contesté la vision africaine du fondateur James McKeown, qui 
dirigea l'Église jusqu'en 1982, ni le paradoxe d'un James McKeown dirigeant sans discontinuer l'Église alors qu'il prônait depuis le début la nomination de pasteurs noirs.

3 Sandra Fancello raconte comment elle a commencé à étudier le phénomène pentecôtiste dans un espace rural du pays mossi au Burkina Faso, terrain d'enquête bien connu grâce aux travaux de Pierre-Joseph Laurent. Terrain où les Églises chrétiennes se frayent un chemin dans un monde en partie musulman. Elle raconte le tournant de sa recherche "lorsque fit irruption la croisade d'évangélisation des pasteurs ghanéens, à Ouagadougou, et qui donnait soudain sa dimension transnationale à l'Église dans laquelle j'avais commencé à travailler localement. À partir de ce moment, l'Église de Pentecôte, que j'avais perçue comme une Église "rurale" (ce qu'elle est aussi, par d'autres aspects), s'est donnée à voir dans sa dimension singulière, à la fois rurale et "indigène" par son attachement aux langues vernaculaires (le möré au Burkina, le twi au Ghana et ailleurs), et transnationale, profondément moderne par les moyens qu'elle se donne» (p. 20). Tout un chapitre est consacré au Burkina Faso. S'y tissent les articulations au plan coutumier entre le « groupe de sortie du groupe » et les croisades transnationales d'évangélisation.

Quand Sandra Fancello débarque à Accra, elle s'initie à la formation historique du réseau de la Church of Pentecost. Celui-ci se développe dans le cadre de la diaspora et de l'expansion missionnaire le long de la côte du golfe de Guinée. Deux types de réseaux, un réseau de fidèles et un réseau de dirigeants. Ces deux approches se recoupent cependant à "travers la question du rôle des Églises dans la formation de circuits migratoires et dans la "recommunautarisation" des fidèles migrants en milieu urbain » (p. 22). On finit parfois par retrouver les mêmes individus à Accra, Abidjan, Bruxelles ou Paris.

5 La partie centrale du livre est consacrée à la politique de la délivrance. Elle se remet un moment sur les traces des travaux de Birgit Meyer. En fait, la naissance de la Church of Pentecost est en partie liée au débat sur la guérison divine. En effet, si ce n'est pas un Africain qui est la figure de proue de ce pentecôtisme indigène, c'est en rapport avec la position de celui qui était destiné à occuper cette place, le Ghanéen Peter Anim et qui était très réticent - contrairement à James McKeown - au recours à la bio-médecine. Ce qu'il y a de singulier dans la pratique de délivrance déployée dans les «camps de prière ", c'est justement le fait que la witchdemonology a été appropriée par de nombreuses Églises qui œuvrent dans ces camps - conception inspirée de grandes figures de ce qu'on appelle le "néo-pentecôtisme » comme les Américains, Kenneth Hagin et Peter Wagner. La witchdemonology est une synthèse de notions occidentales et africaines relatives à la sorcellerie. Les termes de sorciers sont traduits comme équivalents à des démons et les prêtres traditionnels sont vus comme des sorciers. De cette conception, il découle qu'on perçoit la famille élargie comme une force malfaisante - la famille traditionnelle liée au culte des ancêtres est attachée à la sorcellerie - et qu'on va prôner la famille nucléaire. À partir de cela, vont se réorganiser les circuits migratoires. La politique de délivrance de la Church of Pentecost ne s'aligne certes pas en tous points sur cette conception, mais elle pousse quand même cette Église pourtant « classique » sur un terrain parfois proche du " néopentecôtisme ». Tenant compte de l'importance des camps de prière dans le processus migratoire, voilà donc un trait qui va marquer la transnationalisation des circuits missionnaires. L'auteure propose une description parfois très colorée des techniques de 
délivrance, sans en évaluer les conséquences sociologiques sur les traits de la transnationalisation.

6 Sur la question de la transnationalisation, Sandra Fancello se fixe un peu conventionnellement sur les politiques identitaires. L'approche est justifiée, mais aurait mérité d'être dépassée. Une partie est néanmoins particulièrement intéressante, celle portant sur les enjeux politiques de la langue liturgique. C'est l'adoption des langues vernaculaires comme langues liturgiques qui constitue une des formes de « l'indigénisation » du culte, affirme-t-elle. «Plus qu'un ingrédient d'ordre liturgique, l'usage de la langue twi par les fidèles Ashanti se présente comme le marqueur identitaire le plus fort au sein de la communauté transnationale des fidèles » (p. 241). Cela implique une forme de réappropriation des «termes vernaculaires associés aux dieux païens de la société traditionnelle». Et l'auteure de cerner tous les enjeux de l'usage de l'anglais de certaines Églises au Ghana, de la proximité des Agnis en Côte d'Ivoire avec les Ashanti au Ghana et les défis de l'ivoirité, de l'usage du möré au Burkina Faso et de son caractère inapproprié pour traduire certaines expressions bibliques, le tout donnant finalement une place grandissante au français dans la pratique des cultes. Dans bien des cas, ces enjeux se négocient sous la forme de dissidences, par la suite réincorporées. Elle reprend l'interprétation de Birgit Meyer selon laquelle l'usage des langues vernaculaires privilégie une traduction en termes de "diabolisation » de certaines catégories préexistantes au christianisme comme le culte des ancêtres. Mais dans une phase ultérieure, c'est l'usage même de la langue vernaculaire qui est diabolisé cette fois par les «néo-pentecôtistes ». S'insère ici à nouveau cette dialectique déjà signalée entre "pentecôtisme classique " et "néopentecôtisme».

7 Le travail ethnographique sur les quatre terrains principaux de la recherche - le Burkina Faso, la Côte d'Ivoire, la France et le Ghana - est détaillé et permet de toucher de près la manière dont les habitants de ces différentes régions vivent la transnationalisation, dans leur culte, mais également dans leurs relations quotidiennes. Le livre se termine par la description, étape par étape, d'une passionnante observation participante de l'auteure à une crise de direction dans l'Église de Pentecôte de Paris. Cette tension, qui va se conclure par une dissidence, manifeste les crises identitaires de l'impérialisme akan à l'épreuve de l'ivoirité. La nomination d'un président ivoirien dans l'Église de Pentecôte de France trahissait le souci de nommer autant que possible un dirigeant «autochtone ». En l'occurrence, il n'était pas français mais au moins était-il francophone. Or, un dimanche de juin 2003 «alors que les fidèles s'étaient réunis pour le culte, le bruit circulait dans l'“assemblée en français" de Saint-Denis, qu'à l'issue du Conseil International annuel de l'Église qui s'était tenu à Accra au mois de mai, le président de l'Église de Pentecôte de France avait été “limogé” » et qu'un Ghanéen, ne parlant de surcroît pas français, avait été nommé pour le remplacer. Sandra Fancello raconte l'ambivalence de sa situation de complicité devant à la fois suivre le mouvement de protestation et de dissidence et participer à ses réunions en donnant l'impression à ceux qui respectaient la décision d'Accra qu'elle ne prenait pas parti. Le livre se termine dans une description imagée de ces va-et-vient.

8 Livre admirable par sa description de tout un ensemble de processus, premier livre portant sur une Église transnationale pentecôtiste africaine, analyse de l'ambivalence d'un «pentecôtisme classique» contigu avec certaines inflexions du «néopentecôtisme ", le lecteur intéressé par la transformation du monde d'aujourd'hui - 
notamment dans ses manifestations migratoires - y découvrira une merveilleuse observation de la vie concrète en même temps que rituelle de l'Afrique et de sa contiguïté culturelle avec l'Europe. Peut-être reste-t-on un peu sur sa faim quant à l'étude plus directe de la transnationalisation - et notamment de la comparaison avec d'autres Églises pentecôtistes ou « néo-pentecôtistes » transnationales -, de même aussi quant au champ historique dans lequel se développe le pentecôtisme - qui se traduit par quelques trous bibliographiques: pas de référence par exemple au classique de Walter Hollenweger. Sandra Fancello insiste beaucoup sur sa méthode multi-localisée et c'est l'originalité incontestable de son approche à l'issue d'un travail patient, dévoué à l'observation des rapports concrets de chaque communauté et qu'on suit de bout en bout sans se lasser. Voilà un livre attachant, qui dépasse de loin son champ de spécialisation. 